\title{
Configurações
}

Revista de sociologia

\section{À vista (des)armada: casais de mulheres e expressão pública dos afetos}

Under the public eye: Female same-sex couples and the public expression of

affections

À l'œil nu: Couple de femmes et la expression public de l'affection

\section{Tânia Cristina Machado}

\section{CpenEdition}

\section{Journals}

\section{Edição electrónica}

URL: http://journals.openedition.org/configuracoes/2604

DOI: 10.4000/configuracoes.2604

ISSN: 2182-7419

\section{Editora}

Centro de Investigação em Ciências Sociais

\section{Edição impressa}

Data de publição: 30 Junho 2015

Paginação: $49-70$

ISBN: 1646-5075

ISSN: 1646-5075

\section{Refêrencia eletrónica}

Tânia Cristina Machado, " À vista (des)armada: casais de mulheres e expressão pública dos afetos », Configurações [Online], 15 | 2015, posto online no dia 01 setembro 2015, consultado o 20 abril 2019. URL : http://journals.openedition.org/configuracoes/2604; DOI : 10.4000/configuracoes.2604

Este documento foi criado de forma automática no dia 20 Abril 2019 


\title{
À vista (des)armada: casais de mulheres e expressão pública dos afetos
}

\author{
Under the public eye: Female same-sex couples and the public expression of \\ affections \\ À l'œil nu: Couple de femmes et la expression public de l'affection
}

Tânia Cristina Machado

\section{Notas introdutórias: do género, da sexualidade, da classe e do espaço público}

1 Abordar as manifestações afetivas perpetradas por e entre mulheres no espaço público parece remeter para paradoxos múltiplos se se atender ao que, historicamente, tem sido definido, por um lado, como legítimo de ocorrer nesse espaço, por outro lado, como forma ideal de ser mulher, e ainda por outro e de forma associada, como norma no que respeita à sexualidade. Como tal, analisara forma como a intimidade transpõe, ou não, as fronteiras simbólicas do espaço público implica ter em linha de conta as representações de género e de sexualidade que são alocadas a esse espaço e que atuam como normas reguladoras das performances individuais, designadamente no que à expressão dos afetos diz respeito. Implica, portanto, proceder ao mapeamento dos traços que definem ontológica e historicamente o espaço público por oposição ao espaço privado, bem como à reconstrução das dinâmicas complexas entre os eixos de género, de classe e de sexualidade que contribuíram para o configurar, gradualmente, em locus de exclusão e invisibilidade, primeiro, e de potencial esfera de transgressão, depois.

2 A primeira peça essencial para a montagem do cenário que aqui se quer traçar, que se constituirá como pano de fundo facilitador da compreensão das estratégias mobilizadas por casais de mulheres para gerir a sua intimidade conjugal no espaço público, é a reconstrução sintética do processo histórico-social de separação dos espaços público e privado e do seu impacto nas relações e vivências de género e de sexualidade. Os séculos 
XVIII - a partir da sua segunda metade - e XIX têm sido apontados como aqueles que veem emergir os processos de industrialização e da concomitante afirmação da burguesia como classe social dominante, aos quais surge associada a delimitação de dois espaços diferentes, (quase) mutuamente exclusivos e palcos de atividades distintas: o espaço público do trabalho e da política e o espaço privado da família e da privacidade (Bondi e Domosh, 1998; Mota, 2006; Aboim, 2008; Hunt, 2009; Perrot, 2009). Apesar de esta categorização espacial já estar presente, de alguma forma, noutros tempos históricos (Habermas, 1991; Sennett, 1977), foi desde a modernidade que os espaços públicos e privados foram, de forma mais vincada, definidos e separados, atendendo à sua localização - fora ou dentro de casa, respetivamente - e, devido à lógica económica capitalista e industrial emergente, à sua função - produtiva ou reprodutiva (Slater, 1998). Desta distinção decorre a definição do espaço público como a esfera da produção, situada fora de casa e protagonizada pelos homens, e do espaço privado enquanto local de reprodução feminizado (Slater, 1998; Perrot, 2009; Mota, 2010).

Dois fatores funcionaram de forma integrada para que o ajuste entre espaço e género viesse a ganhar forma. Com base em Sennett (1977), pode dizer-se que o primeiro diz respeito a uma pressão de privatização, que veio assolar a sociedade burguesa devido a algumas alterações decorrentes do capitalismo industrial emergente. A "mistificação" da vida em público é uma delas, e, em estreita ligação com as tendências de massificação e de mercadorização, veio nebular a distinção de classe no espaço público e provocar anseios quanto a quem estava do lado de lá no cenário interativo. A crença de que os ornamentos levados para o espaço público, como seja o vestuário, tornavam clara a personalidade - e, acrescenta-se aqui, o lugar de classe - de cada um impulsionou o receio, por parte dos burgueses vitorianos, de ausência de controlo sobre a forma como se apresentariam publicamente e de transmissão involuntária de sinais que não correspondiam àqueles que queriam que fossem apreendidos pelos outros (ibidem). Num movimento de proteção face ao contexto social delineador das suas condições de existência, a recolha ao espaço privado, conotado com a esfera familiar e estável, surge como efeito da imprevisibilidade, tanto económica como relacional, experienciada no espaço público, de onde decorre o reforço das fronteiras entre ambos e da alocação de uma maior aura de moralidade ao primeiro (ibidem; Mota, 2010). Talvez como resultado de uma resposta inconsciente ao limbo instável, desordenado e pouco previsível em que se sentia viver, a classe burguesa protagoniza a imposição de uma ordem de género e sexual enraizada espacialmente. $O$ segundo fator é, então, o que corresponde à imposição de uma moral puritana que constituiu o pilar a partir do qual se procedeu à divisão do trabalho e dos papéis sexuais nos espaços público e privado e, consequentemente, à sua generização e (as)sexualização. Num ímpeto de afirmação da sua posição e legitimidade sociais por via da diferenciação face às restantes classes suas contemporâneas - a aristocracia e a plebe -, de acordo com Brandão (2007: 46), a burguesia elege as mulheres como a plataforma por excelência de demonstração da moral, da conduta e da feminilidade ideais. A domesticidade e a maternidade são assumidas como representativas das formas adequadas de ser mulher, associadas a demonstrações de castidade, recato e pudor (ibidem). É construído um guião que orienta as performances de feminilidade, tanto em termos de conteúdo, como de cenário espacial, de forma a regular, num âmbito mais amplo, as performances de classe e a manter os elementos simbólicos distintivos sustentadores da posição da burguesia na hierarquia de classes. Um desses elementos é a "respeitabilidade" feminina, que devia ser assegurada através de comportamentos apropriados no espaço público que permitissem, por sua vez, perceber a existência de uma convergência com os padrões de classe média 
no espaço privado, nomeadamente, por via da linguagem ou das regras de etiqueta (Slater, 1998). Ser uma mulher adequada implicava, portanto, a função de manter o estatuto social publicamente reconhecido dos homens (Brandão, 2007: 47), o que implica, numa dinâmica paradoxal, a dependência destes face àquelas para a manutenção da sua primazia de classe e de género. Ora, as ansiedades daqui decorrentes, justificadas pelo receio, por parte dos homens, de serem socialmente desacreditados no espaço público por condutas inapropriadas das esposas, levaram à regulação apertada da sexualidade feminina, no sentido de a manter no espaço privado (cf. ibidem). Este movimento de clausura da sexualidade das mulheres é reforçado pela atribuição de um significado de amoralidade à presença feminina no espaço público: figurar nele sem estar sob os auspícios de um homem significava arriscar a sua virtude e cair em desgraça (Sennett, 1977). Significava, por arrastamento, a possibilidade de desgraçar e desvirtuar os seus maridos, surgindo a necessidade de as manter no espaço "certo".

Este processo é facilitado, entretanto, pelas contribuições de várias dinâmicas distintas em coocorrência no período em análise. Uma delas é a emergência e o estabelecimento do que Giddens (1992) designa por "amor romântico" como modelo relacional dominante, associado a relações de exclusividade ao abrigo do casamento - sendo já desprovido de interesses económicos e baseado no amor e na afetividade -, a desejos e prazeres emocionais mais do que sexuais e às ideias de complementaridade ou de fusão conjugal. De forma imbricada, e na linha da perda de importância da fisicalidade sexual das relações conjugais (ibidem), o ascetismo burguês deu o seu contributo para a convergência da sexualidade com a procriação. A prática sexual sem propósitos procriativos passa a ser vigorosamente reprimida por se incompatibilizar com uma entrega forte e total ao trabalho, com base na ideia de que a força de trabalho não poderia "dissipar-se nos prazeres, salvo naqueles, reduzidos ao mínimo, que lhe permitem reproduzir-se" (Foucault, 1999: 11). Até ao final do século XIX as atividades sexuais não procriativas, principalmente quando incluíam perda de sémen, eram consideradas debilitantes devido ao consumo de energia, o que implicava o enfraquecimento corporal e cerebral e a perda de faculdades mentais (Moita, 2001: 64). A importância atribuída à contenção sexual parece estar relacionada com um estilo de vida que já implicava uma postura de contenção económica e à crença de que a emissão não controlada de sémen significava gastar força e energia essencial que deviam ser aplicadas no trabalho (Greenberg, 1988). Paralelamente, assiste-se à valorização da maternidade como papel a ser desempenhado pelas mulheres, na esteira da valorização dos laços emocionais entre pais e filhos, da diminuição da dimensão das famílias e do reconhecimento da fragilidade das crianças e da necessidade de lhes prestar cuidados a longo prazo (Giddens, 1992: 53). Concomitantemente, o espaço do lar é reforçado como esfera conjugal, familiar, reprodutiva e íntima por oposição ao espaço público produtivo, habitado por estranhos fracos laços de proximidade, vincando-se, desta forma, em função de todas as transformações em curso, a divisão espacial dos sexos e da sexualidade que alocaria, ainda com mais afinco, as mulheres e as demonstrações afetivas à privacidade do lar. Sobretudo quando não convergentes com a norma (heteros)sexual emergente à data, implementada pela proliferação de discursos médicos em torno do sexo (Foucault, 1999), os afetos não deviam nunca, na melhor das hipóteses, extravasar para fora do espaço privado, dando lugar a um processo de "dupla privatização" das mulheres em função do seu sexo e da sua sexualidade. 
5 Entretanto, ao longo dos séculos XX e XXI a ordem de género foi alterada e a delimitação diferenciada dos espaços público e privado foi esbatida, em decorrência de transformações ao nível do estatuto social e do papel das mulheres (Aboim, 2008). E esta é a segunda peça necessária para a montagem do puzzle cénico que se pretende traçar para servir de suporte à análise das expressões afetivas, por parte de casais de mulheres, no espaço público. De facto, a invasão física do espaço público por parte dos movimentos feministas permitiu, simultaneamente, desafiar o modelo de feminilidade dominante e "privatizar", ainda que parcial e intermitentemente, o espaço público através da "publicização" do privado. Aliás, "o pessoal é político", slogan feminista que serviu de mote à segunda vaga do feminismo, imortalizado por um texto de Carol Hanisch ${ }^{1}$, e que abriu portas ao movimento LGBT, dá conta da permeabilidade do espaço público à entrada de elementos subversivos da sua estabilidade territorial e simbólica e das suas normas de funcionamento, designadamente no que respeita às performances de género e de sexualidade.

6 Ao proporcionar visibilidade a outras formas de ser mulher, o espaço público tem sido configurado como locus de transgressões múltiplas, interrelacionadas, atendendo às origens da configuração dominante da feminilidade: territorial, de género, de sexualidade e de classe. Como tal, as suas fronteiras têm sido deslocadas e erodidas, no sentido em que, segundo as teses de Sennett (1977), tem sido "tiranizado" pelas questões anteriormente tidas como íntimas e privadas, e, ao mesmo tempo, tem invadido e regulado o espaço privado (Aboim, 2008). Este movimento bidirecional de diluição de fronteiras é coadjuvado por transformações sociais mais amplas a decorrer em simultâneo, particularmente, os processos de individualização (Beck e Beck-Gernsheim, 2002), de plasticização da sexualidade (Giddens, 1992) e de sexualização da cultura (McNair, 2002; Atwood, 2006, 2010).

7 o primeiro diz respeito à emergência do homo optionis, i.e., da crescente possibilidade de os indivíduos decidirem, entre uma amálgama de opções disponíveis, aquelas que querem integrar na sua experiência quotidiana (Beck e Beck-Gernsheim, 2002). Assenta na desintegração de categorias anteriormente tidas como fixas e ordenadoras da existência social dos indivíduos, como sejam a família, a classe social ou o género (ibidem), e, portanto, na maior liberdade de escolha associada à possibilidade de os indivíduos recolherem fragmentos de diversas categorias para "se montarem" e se experienciarem. Isto possibilita, ajustando ao caso que para aqui importa, que as mulheres construam uma identidade de género distanciada dos conteúdos tradicionais enquadrados pelo binarismo (masculino/feminino), pela complementaridade (homem/mulher) e, em consequência, pela heterossexualidade e pela procriação, reclamando-se como pilotos da sua própria vida, do seu próprio corpo e das suas potencialidades reprodutivas, dentro e fora do espaço privado. A ideologia da liberdade individual incorpora o espaço privado e progride, gradualmente, para o espaço público como aquela que assumirá o comando do seu funcionamento, proporcionando a visibilidade de modos de ser mulher alternativos em coexistência.

8 Na sequência desta lógica de escolhas múltiplas, a intensificação da "sexualidade plástica" (Giddens, 1992) veio também alterar a forma como a intimidade e a sexualidade podem ser experienciadas. Enquanto centrada no prazer individual e não na finalidade reprodutiva, este tipo de sexualidade afigura-se moldável aos objetivos de cada um, podendo tanto romper com a dinâmica causa-efeito tradicionalmente associada ao ato sexual - sendo a procriação tanto a causa, como o efeito -, como reproduzi-la sem que, 
por isso, deixe de obedecer ao princípio do prazer que lhe subjaz. Passando a sexualidade a ser baseada apenas nos gostos e nas preferências individuais e a assumir uma configuração volátil e maleável, passa também a ser considerada como uma componente do self (ibidem). Como tal, passa a integrar a identidade dos indivíduos e, nalguns casos, a assumir-se como traço central de identificação, como seja o caso daqueles com identidades sexuais não normativas que, em função da partilha desta característica comum, passaram a mobilizar-se ativamente no espaço público com a finalidade de adquirir direitos de cidadania (cf. Richardson, 2004; Weeks, 1986). Desta feita, o espaço público é impregnado de sexualidade mesmo que sem disso se dê conta, na medida em que os indivíduos que nele se movem, independentemente da maior ou menor visibilidade que lhe dão, para lá transportam o seu self sexual quotidianamente, que é reconstruído pelas normas do espaço e, paralelamente, as reconstrói à medida que se vai exteriorizando.

De forma interrelacionada, e numa dinâmica de influência mútua face aos processos anteriores, emerge aquilo que McNair (2002) chama de sexualização da cultura e de democratização do desejo, referentes ao florescimento de uma cultura sexual mais pluralista e diversificada e à expansão do acesso de todos os indivíduos a uma panóplia de meios de expressão sexual. De acordo com Atwood (2006), uma cultura sexualizada espelha uma maior permissividade sexual, a emergência de novas formas de sexualidade ou a decadência de categorias que visam normalizar determinados tipos de sexualidade e colocar outros à margem da norma, mas também o maior burburinho público em torno de questões de moral e decência no que às práticas e identidades sexuais diz respeito. Se, por um lado, esta tendência tem permitido sobrecarregar o espaço público com discursos sobre sexualidade e com performances de índole afetiva e reposicionar, expandindo, as delimitações do que é, ou não, legítimo ocorrer entre fronteiras públicas, por outro lado, tem permitido, à semelhança do que Foucault (1999) deu conta a propósito do processo de "discursificação do sexo", proceder a novas categorizações sexuais e ao reforço de uma norma sexual que define, por proximidade ou afastamento das suas prescrições, quais as práticas e as identidades sexuais "normais" ou "desviantes", com implicações ao nível da sua (des)integração no espaço público. O acesso a uma diversidade de discursos e conteúdos em torno do sexo e da sexualidade através dos meios de comunicação impulsionou a emergência de uma "cultura striptease", nos termos de McNair (2002), caracterizada, entre outras coisas, pela preocupação com a autoexposição pública no que às práticas e às identidades sexuais diz respeito, mas, paradoxalmente, abriu portas à sua maior regulação (Atwood, 2006) e ao reforço do que Rodó-de-Zárate (2013) chama de heteronormalização do espaço público. Isto é visível através do surgimento constante de novas categorias de identificação no campo das sexualidades, do género e da intimidade (e.g., assexualidade, pansexualidade, ginessexualidade, escoliossexualidade, queer, bigénero, pangénero, poliamor), que, apesar de serem revestidas de carácter de utilidade em termos de identificação personalizada e de aquisição de visibilização e legitimação dos indivíduos que nelas se enquadram, contribuem para a sua deslocação para o campo do "desvio" e, até, da patologização, minando as suas possibilidades de movimentação livre e igualmente legítima no espaço público.

10 Ao mesmo tempo que o espaço público tem sido sujeito a reconfigurações que têm deslocado as suas fronteiras e os seus requisitos no que respeita às performances de género e de sexualidade passíveis de nele serem albergadas, tem acabado por ser foco de reprodução de alguns elementos simbólicos integrantes das conceções dominantes do que 
é ser mulher. Numa dinâmica antonímica, à medida que se abre uma maior diversidade de possibilidades no âmbito da sexualidade, na esteira de um conjunto de transformações sociais que têm vindo a equipar os indivíduos com uma maior capacidade de escolha, de liberdade e de agência, aumenta também o espectro de dispositivos simbólicos reguladores das sexualidades e das demonstrações íntimas adequadas, e, consequentemente, a necessidade de mobilizar estratégias de gestão da identidade sexual no espaço público. É neste movimento de vaivém entre configurações espaciais, de género e de sexualidade da modernidade e da modernidade tardia que se situam as práticas de gestão e expressão dos afetos de casais de mulheres fora do espaço do lar, que servem de mote a este artigo.

11 Os dados empíricos são provenientes de entrevistas semiestruturadas a 40 mulheres, residentes em Portugal, que integram casais do mesmo sexo com filhos planeados conjuntamente, realizadas no âmbito de uma investigação em curso que assume como objeto teórico as representações daquelas acerca da maternidade e as suas estratégias de gestão das identidades maternais e sexuais. A gestão dos afetos em espaço público emerge nos discursos de quase todas as entrevistadas ao abordar a forma como gerem as identidades quotidianamente. A duração das entrevistas foi de uma a duas horas, e a informação recolhida foi sujeita a uma análise de conteúdo temática.

12 A maioria das entrevistadas reside na região de Lisboa e regiões limítrofes e tem 35 ou mais anos. Quanto às classes sociais de origem, há uma representação mais ou menos igualitária de classes do meio/topo da hierarquia e da base.

\section{Conformidade aos afetos heteronormativos no espaço público}

13 Já Goffman (1963) demonstra que, historicamente, o espaço público é um cenário a ser habitado somente por aqueles que, a dado momento, se consideram "adequados" para tal. Basta pensar na sua referência a como os gregos imprimiam sinais corporais naqueles escravos, criminosos ou traidores - que consideravam possuir alguma característica que abalava o seu estatuto moral, i.e., um estigma, de forma a distingui-los como demasiadamente "poluídos" para figurar livremente naquele espaço (ibidem). o espaço público dispõe, portanto, de mecanismos que se encarregam de garantir que aqueles que nele se movem correspondem a um perfil "legítimo", em função dos seus ditames de funcionamento. Nem sempre são mecanismos visíveis, sendo, aliás, aqueles que não o são os mais perniciosos e os que mais poder exercem sobre a modelação das performances públicas dos indivíduos, porque atuam ao nível do inconsciente. Exercem, neste sentido, aquilo que Bourdieu e Passeron (1970) designam de violência simbólica, cujo efeito se espelha no reconhecimento, por parte, no caso, dos casais de mulheres, da legitimidade das regras de conduta "apropriada" impostas pelo espaço público e da sua interiorização como balizas do que podem ser e fazer fora da privacidade do lar. Um desses mecanismos simbólicos é, precisamente, a ideologia da heteronormatividade, que encerra em si um conjunto de premissas que definem a heterossexualidade como forma de prática sexual "natural" e "normal", cujo contraponto com outras formas de sexualidade as leva a serem definidas como "marginais" ou "desviantes", e, de forma associada, que concebem ideais de masculinidade e de feminilidade assentes na complementaridade sexual. A interiorização destes elementos faz com que se convertam em disposições para agir, o que significa que, sendo que as disposições funcionam como princípios duráveis de 
organização e geração da ação e que, apesar de estruturadas a partir de campos específicos de ação, são dotadas de transferibilidade de uns campos para os outros (Bourdieu, 2002), mesmo os indivíduos que, em termos de identidades de género e sexuais, subvertem as ideologias e as práticas dominantes, regem as suas condutas, tanto públicas, como privadas, em consonância com os requisitos normativos do espaço público. Ao fazê-lo, reconhecem ser portadores de um estigma, de uma característica que marca a discrepância entre a identidade social e a identidade virtual, i.e., entre a identidade que, de facto, é a sua e que reclamam para si e aquela que, no cenário interativo, lhe é imputada pelos outros a priori (Goffman, 1963). A tentativa de ocultar esta discrepância dá azo à construção de personagens cujas performances sejam convergentes com as normas do espaço público, como duas entrevistadas dão conta no excerto abaixo:

L.: Há coisas que uma pessoa tem mais cuidado na linguagem, não é?

M.: Mais no trato uma com a outra [...], que é para não estarmos a chocar ninguém, digamos assim. Não é que a gente se porte mal quando estamos sozinhas, também não é...

L.: Mas como disse a [nome de uma amiga], foi a primeira vez que foi a um casamento e não viu um beijo.

M.: [...] Tentamos não chocar. [...] as pessoas não estão habituadas e, lá está, no casamento não houve beijo. (Lídia e Marcenda, 41 e 39 anos, $\mathrm{PTE}^{2}$ e PTE, distrito de Setúbal)

14 A ideia da prevenção do "choque", do desconforto, do incómodo e, até, da ofensa, e do confronto provocados por expressões afetivas não normativas aos outros indivíduos presentes no espaço de interação foi já aludida noutras pesquisas (Gabb, 2005; Ferreira, 2011; Oliveira, Gonçalves e Nogueira, 2013) e reflete bem a forma como as disposições incorporadas num contexto de heterossexualidade normativa se sobrepõem a outras quando as mulheres se situam num palco público, atuando de forma a fazer confluir as suas condutas individuais com os guiões sexuais hegemónicos. Esta pista já foi notada por outros autores (Blidon, 2008; Costa, Oliveira e Nogueira, 2010; Ferreira, 2011), dado também terem concluído que a demonstração pública de afetos é, regra geral, pouco comum entre casais de pessoas do mesmo sexo, mesmo que, de acordo com Ferreira (2011), a relação afetiva seja do conhecimento de pessoas que lhes são próximas familiares ou amigos. A referência das entrevistadas à ideia de "bom comportamento" mesmo quando não estão sob olhares externos demonstra que, ainda que não necessária, a máscara normativa é, de algum modo, posta e continua a incitar à obediência às regras no espaço privado, acabando por delimitar o grau de expressão afetiva. Ferreira (ibidem) também dá conta desta dinâmica de ocultação dos afetos em espaços que, ainda que não públicos, são aparentemente recetivos à diversidade sexual - os espaços gay friendly. Isto remete para a ideia de que a posse de um estigma, mesmo quando "desacreditável" ou não imediatamente percetível (Goffman, 1963), sendo reconhecido como tal pelo seu possuidor, impele à gestão constante das impressões dadas intencionalmente e à autovigilância quanto às impressões transmitidas involuntariamente aos outros em situações de copresença física (Goffman, 1993). Mas também pode conduzir, nalguns casos, à sua assunção como não diretamente responsável pelo tipo de impressões veiculadas, pelo facto de os tipos de ações levadas a cabo no espaço público serem vistas por quem as desempenha como decorrentes de traços de personalidade. As palavras de duas entrevistadas demonstram este ponto de vista, quando referem que a ausência de demonstrações públicas de afeto decorre da sua forma "natural" de ser:

Entre nós, não somos do género de andar aos beijinhos à frente das outras pessoas, mas não somos, de todo. Mas é uma coisa natural em nós. Nós também não somos 
assim na rua. (Isaura, 46 anos, EDL3, distrito de Lisboa) É assim: nós não somos de manifestações públicas, mas isso acho que não tem a ver com o facto de ser homo ou heterossexual. (Amélia, 35 anos, PTE, distrito de Coimbra)

15 Esta perspetiva converge com o argumento de Gabb (2005), segundo o qual a não exteriorização de afetos no espaço público resulta, em parte, da partilha comum da ideia de que estes devem ter lugar no espaço privado, independentemente do tipo de relação amorosa a que dizem respeito. Este facto desajusta-se, no entanto, da realidade portuguesa, em particular, e da Europa do Sul, em geral, onde demonstrar afeto por outrem publicamente constitui um traço cultural distintivo (Ferreira, 2011; Rodó-deZárate, 2013). Como tal, remete para a existência de uma cultura de expressão afetiva dual permeada pela ideologia heterossexual normativa, culminando na existência de um espaço público libertário para aqueles que partilham, incorporam e exteriorizam os pressupostos ideológicos dominantes, e de um espaço público repressivo para aqueles que assumem identidades e práticas sexuais distintas. Este facto é vertido no argumento de Valentine (1993), de acordo com o qual os casais de sexo diferente exibem a relação afetiva que os une de forma mais ou menos "natural", dada a hegemonia "natural" da heterossexualidade enquanto modelo relacional e afetivo. Isto impregna o espaço público, aparentemente neutro (Bell e Valentine, 1995; Browne, Lim e Brown, 2007) e não sexuado, de elementos simbólicos que regulam as expressões afetivas no sentido de as permitir quando socialmente legitimadas e de as reprimir quando caindo fora da norma. Contudo, este poder simbólico, menos físico e visível, exercido sobre os indivíduos pode dar a alguns deles uma falsa sensação de controlo sobre as suas formas de interação e de re/ apresentação, na medida em que se percecionam como estando deliberadamente a escolher não se apresentar de determinada maneira no palco público. Outros, entretanto, percebem o constrangimento de que estão a ser alvo e "escolhem" não expor as suas relações afetivas fora do espaço do lar. As palavras de um dos casais entrevistados permitem demonstrar esta perspetiva:

Mas há uma coisa que não fazemos e que eu gostava de fazer, que era andarmos de mãos dadas. // Não, não posso fazer isso porque a [nome da companheira] sente-se mal com isso. (Amélia, 35 anos, PTE, distrito de Coimbra)

16 Esta "escolha", contudo, não é feita sem que haja uma negociação pré- via no seio do casal e uma consensualização das suas apresentações públicas, algo de que também Ferreira (2011) e Ródo-de-Zárate (2013) já tinham dado conta nas suas pesquisas. Reassumindo a abordagem goffmaniana (1963), pode argumentar-se, a partir desta dinâmica negocial, que o estigma só é reconhecido e experienciado como tal por parte das mulheres que integram estes casais nos momentos em que ambas se encontram em simultâneo no mesmo espaço. Caso contrário, cada uma delas passará, até prova em contrário, por "desacreditável", i.e. por mulher heterossexual, não tendo de se submeter a uma ética de gestão de impressões tão rígida. Ródo-de-Zárate (2013) também teve oportunidade de concluir algo semelhante na sua pesquisa, argumentando que, se as aparências e as performances das mulheres forem convergentes com o que se espera que uma mulher pareça e faça, a sua identidade sexual passa despercebida, principalmente se circularem sem as respetivas namoradas/parceiras no espaço público. No caso das mulheres entrevistadas aqui em análise, esta estratégia do "passar por" é mais facilmente mobilizada e mais bem sucedida se as mulheres se fizerem acompanhar dos fi lhos, pois o pressuposto da maternidade aproxima-as, aos olhos dos outros, ao ideal de feminilidade normativo. De facto, entre os casais em que se deu conta da existência de uma negociação mais vincada, mais discutida e menos tácita, foi sempre a perspetiva da mãe gestante que 
preponderou na estratégia de (in)visibilização a adotar no espaço público. Curiosamente, são precisamente estas mulheres que melhor representam o papel "da mulher", em termos de expectativas sociais, pois assume-se, aquando da sua entrada no cenário interativo, que, sendo mães, não podem ser outra coisa que não heterossexuais. Isto levanta uma questão de poder diferencial do estigma, na medida em que, apesar de ambas as mulheres do casal possuírem uma identidade sexual não normativa, parece ser aquela que, se considerada isoladamente, apresentar o estigma menos visível no espaço público que sai beneficiada, na medida em que a sua estadia nesse espaço será menos atribulada $\mathrm{e}$ requererá menos esforço de manipulação identitária, sendo-lhe reconhecido, de forma acrescida, um estatuto legítimo enquanto mulher que obedece, supostamente, a todos os padrões do feminino.

17 Esta dinâmica de negociação é, então, à partida, desigual em termos de poder possuído por cada uma das mulheres do casal para fazer preponderar a sua perspetiva na decisão final, justificada pelos também desiguais vínculos biológicos e legais com os fi lhos do casal. Esta desigualdade biológico-legal interfere, nalguns casais, incluindo naqueles aqui em análise, na forma como outras decisões quotidianas são discutidas e tomadas, sendo, regra geral, a mãe gestante, com laços biogenéticos legalmente reconhecidos com a criança, aquela que decide a direção a tomar no que respeita a várias decisões de âmbito conjugal e familiar, proporcionando, no entanto, à mãe não gestante a sensação de ter contribuído com igual preponderância para as decisões finais.

18 A dimensão de classe social de origem infiltra-se no processo, funcionando como acessório de sustentação da variável anterior. A este respeito, na maior parte dos casos verifica-se uma heterogeneidade intracasais no que respeita à origem de classe, significando que uma das mulheres provém de uma classe mais bem posicionada na hierarquia do que a outra, nem sempre sendo a mãe gestante a ocupar este lugar. À partida, ceteris paribus, i.e, tudo o resto constante, isto remeteria para a existência de casos em que, por possuir maiores volumes herdados de capital económico, cultural, social e simbólico, a mãe gestante conseguia ter maior poder negocial e de imposição da sua perspetiva acerca dos modos de gestão pública dos afetos. No entanto, quando se inclui na análise o estatuto maternal, este pressuposto deixa de ser linear. Independentemente da posição de classe de origem da mãe gestante, aquilo a que se pode chamar volume de capital biogenético, medido pela existência de transmissão de material genético e biológico a outrem, sobrepõe-se sempre aos restantes tipos de capital.

19 É, maioritariamente, em casais em que existem origens classistas privilegiadas - de uma ou ambas as mulheres - que a expressão pública dos afetos é mais contida, o que remete para a permanência de alguns traços caracterizadores da classe média burguesa, nomeadamente, o seu puritanismo e a privatização dos afetos. Este perfil é complementado com o facto de serem, na maior parte dos casos, mulheres mais velhas, o que acaba por implicar a inexistência (ou quase) de indivíduos/famílias com identidades sexuais/configurações não normativas nas suas redes de sociabilidade, bem como fraco ou nulo envolvimento nas ações ativistas em torno de questões LGBT. O facto de se terem movido durante mais tempo num contexto social marcado pela heteronormatividade e pelo patriarcado implica que tenham incorporado um conjunto de disposições que impelem à convergência com uma ordem de coisas que consideram "natural", pois, ainda que não estáticas e eternas, como argumenta Wacquant (2007: 66-67), as disposições subjetivas são dotadas de inércia, impelindo as mulheres a tender à reprodução de alguns dos elementos estruturais que incorporaram e que delineiam formas adequadas de ser 
mulher. Isto inclui um certo pudor e sentido de moral no espaço público, delimitando as relações de sociabilidade e as atividades em que se podem envolver

\section{Destabilizando a normatividade dos afetos públicos}

Se, por um lado, é possível que os indivíduos, quando confrontados com os padrões de práticas e de identidades com legitimidade para ter lugar no espaço público, reconheçam que são possuidores de um estigma que impele à gestão cuidadosa da sua conduta, por outro, segundo Goffman (1963), também é possível que "falhem" em perceber o que é que é esperado deles por considerarem não possuir nenhuma característica que limite as suas formas de apresentação no cenário interativo. Neste caso, o estigma que lhes é atribuído não é por eles autorreclamado e/ou incorporado, de onde resulta a possibilidade de a sua presença no espaço público operar de forma disruptiva face a algumas das regras estabelecidas. Daqui decorre que, apesar da sua estabilidade estrutural enquanto delineadoras das condutas passíveis de ocorrer fora de portas, as regras que sustentam o funcionamento do espaço público são plásticas o suficiente para permitir a sua reconfiguração por via da ação dos indivíduos. São, portanto, permeáveis ao questionamento, ao desafio, à resistência e à transgressão daquilo que ditam (Duncan, 1996; Oliveira, Gonçalves e Nogueira, 2013), o que implica que também o próprio espaço público possa ser equacionado mais como abstração simbólica, sujeita a deslocações subjetivas, do que como algo com materialidade territorial bem delimitada, à qual estão subjacentes normas que se manifestam a um nível corpóreo - contenção ou liberdade na expressão afetiva. Este é o caso de algumas entrevistadas, para as quais existe uma divisão, de certo modo, artificial entre público e privado, na medida em que assume simplesmente como referência as paredes de casa propriamente ditas, não associando nenhum conteúdo simbólico ao lado de dentro e ao lado de fora delas, como tem sido hábito histórico. No que respeita às demonstrações de afeto, o impacto que esta conceptualização, de certo modo vazia de conteúdo, tem é que permite esvaziar as fronteiras entre o que é apropriado fazer em casa e fora dela, levando a intimidade para a rua sem que isso requeira grandes esforços de gestão da situação por parte das mulheres. As expressões afetivas fora de casa adquirem, desta forma, um cariz de banalidade, não deixando, contudo, de ser concebidas como uma forma de transgressão. As palavras de uma entrevistada permitem exemplificar este ponto de vista:

Às tantas, já brincávamos, a dizer que, quando estávamos a dar a mão na rua, estávamos tipo 'ok, agora é um bocadinho de educação para o desenvolvimento, para as pessoas', ou quando dávamos um beijinho, ou qualquer coisa. (Cândida, 30 anos, EE4, distrito de Lisboa).

21 O facto de se referir às demonstrações de carinho como um ato educativo para os presentes no mesmo espaço implica o reconhecimento de que, em confronto com as expectativas deles, estão espacialmente desenquadradas do seu contexto de legitimidade - o espaço privado. Mas não é por isso que as contêm ou que as ocultam. Assumem que são apresentações de si que escapam ao ideário normativo, operam a uma resistência face a este, e, paralelamente, protagonizam, intencionalmente, um conjunto de ações que têm como objetivo naturalizar os significados que têm subentendidos e torná-las inteligíveis aos outros como representativas de mais uma configuração relacional e afetiva possível.

22 Já Costa, Oliveira e Nogueira (2010) tinham dado conta de que ocupar e ganhar visibilidade no espaço público por via de demonstrações de carinho era algo importante 
para alguns indivíduos com identidades sexuais não normativas, o que estará relacionado, precisamente, com a ideia da tentativa de naturalização de identidades sexuais diferentes da normativa. Contrariamente à tese de Goffman (1963), segundo a qual os indivíduos "desacreditados", como um estigma imediatamente visível aquando da sua entrada em determinado espaço de interação, sentem que a sua privacidade está a ser invadida ao perceberem que os outros deram conta da sua característica distintiva, algumas das mulheres entrevistadas abrem voluntariamente espaço à entrada das coisas privadas no espaço público, mostrando vincadamente que a sua identidade sexual é diversa daquela que seria esperado exteriorizar naquele espaço. Ao fazê-lo, incorrem numa estratégia de afirmação do estigma, contrariamente às entrevistadas referidas no ponto anterior, que preferiam ocultá-lo. Algumas vezes, para além de uma afirmação corporal, aderem a uma afirmação verbal, fazendo uso, por exemplo, de termos que são tradicionalmente demonstrativos da existência de uma relação de afetividade entre duas pessoas de sexo diferente e que, quando pronunciados num cenário de interação, permitem presumir, por decalque, por parte dos outros, a existência de uma relação afetiva entre as mulheres. Os dois exemplos abaixo permitem demonstrar esta perspetiva, por via do uso de termos como "amor" e "esposa" nas comunicações verbais quotidianas no espaço público:

C.: Mas, se calhar, estou a falar com ela 'pronto, amor [...], faz assim, faz assado'. Não mordermos a língua, vá, ou seja, não evitamos fazer.

J.: Lá está, não somos de andar nem aos beijos, nem aos abraços, nem de mão dada, mas temos manifestações de carinho verbais. (Justina e Carmen, 39 e 40 anos, AA5 e EE, distrito de Faro)

O que acontece é que nós falamos normalmente. Então, por exemplo, se ela vai à padaria e diz assim 'tem regueifa?' e ele diz 'ah, hoje não temos, temos reservado', ela naturalmente responde 'ah, é que a minha esposa gosta mesmo de regueifa [...]'. (Felícia, 28 anos, PTE, distrito do Porto)

A preferência por uma ou outra forma de afirmação dos afetos assenta no maior ou menor grau de contacto anterior e/ou proximidade das mulheres com os outros presentes no mesmo espaço. Apresentar-se de uma forma que apela mais aos sentidos visuais e, portanto, mais subversiva dos princípios estruturadores da ação passível de decorrer no espaço público implica estar em causa um cenário despojado de qualquer grau de conhecimento prévio dos restantes figurantes. Recorrer a dispositivos verbais tem por base a existência de algum tipo de relação entre as mulheres e os outros presentes, de modo que não se afigura necessário mobilizar estratégias de visibilização mais aguerridas para impor a sua realidade afetiva. Quer uma, quer outra, têm, no entanto, o mesmo propósito e, potencialmente, o mesmo efeito, que é o de destabilizar, simultaneamente, os limites espaciais - públicos e privados - e as conceções de género e de sexualidade, pela rutura que protagonizam face às prescrições da feminilidade normativa.

Contudo, isto só é conseguido até certo ponto. Considerando que o habitus é o produto integrado das experiências passadas dos indivíduos, delineadas pelas estruturas que sustentam os vários campos em que se movem (Bourdieu, 2001, 2002), assumindo que o espaço público como um campo per se, significa que existe sempre uma semelhança mínima comum entre o conjunto de disposições incorporadas e mobilizadas por parte das mulheres entrevistadas e de qualquer pessoa com a qual possam interagir nesse espaço. A partilha do mesmo contexto social de enquadramento das vivências e das práticas determina a sujeição a um conjunto comum de estruturas que enformam, para o caso que aqui interessa, a forma de ser mulher, originando uma componente grupal do habitus que atribui sentido às interações estabelecidas. Todavia, os indivíduos movem-se por vários 
campos e, como tal, adquirem disposições adstritas a determinado tempo e espaço (Bourdieu, 2002), acabando por ser construído um habitus com várias camadas de antiguidade, sem que isso signifique que as mais antigas vão sendo substituídas pelas mais novas na atribuição de sentido às práticas e às experiências. As primeiras acabam sempre por vir à superfície e moldar as ações e as representações individuais, o que explica, por exemplo, a ideia de que a expressão dos afetos no espaço público possa ser vista como uma forma de transgressão, pois só se configura como tal se se reconhecer que existem normas que estão a ser quebradas, o que, por sua vez, significa que há um conjunto de disposições de base a atribuir significado à situação, assente numa tríade de pressupostos associados ao género e à sexualidade: diferença (de sexo), complementaridade (entre os sexos) e heterossexualidade. Apesar das comunalidades que existem, os habitus copresentes em determinado espaço público são, ao mesmo tempo, diferentes, o que pode provocar uma intermitência na inteligibilidade daquilo que está a ocorrer e descoincidências nos significados atribuídos às re/apresentações que estão a ter lugar. Nestas situações, há necessidade de proceder a reorientações de sentido e a um ajuste da definição e da interpretação.

Uma das entrevistadas dá conta da forma como este ajuste teve lugar numa situação em que sentiu necessidade de categorizar explicitamente a outra mulher com quem interagia como sua namorada, num reforço do significado que podia estar a ser, ou não, percebido por quem estava do lado de lá ao gesto de dar as mãos:

Uma vez que eu fui a um café aqui perto [...], estava uma mulher a olhar fixamente para nós e nós estávamos de mão dada em cima da mesa. Ela estava a olhar fixamente para nós e já me estava a irritar. E eu viro-me para ela e disse assim: 'não quer tirar uma fotografia? É que se calhar dura mais tempo do que estar a olhar fixamente! Sim, somos namoradas. Qual é o problema?' (Felícia, 28 anos, PTE, distrito do Porto)

Mobilizando, em simultâneo, disposições provenientes das duas componentes do habitus, a pessoal e a coletiva, os indivíduos têm a capacidade de se apresentar em conformidade com determinadas normas sociais e, ao mesmo tempo, de forma divergente face a outras. No caso das entrevistadas em análise, a sua convergência corporal, em termos de aparência física, com os padrões de feminilidade dominantes implica, no espaço público, a presunção da sua heterossexualidade, pelo que a demonstração de afetos que protagonizam é vista como "inapropriada" para o seu género por parte de quem assiste e de quem não partilha o mesmo habitus sexual. Ainda que o habitus seja construído de forma inconsciente, por via da mobilidade dos indivíduos nos vários campos que constituem a sua esfera de ações e relações, ele acaba por possuir uma componente de intencionalidade e reflexividade, de onde resulta que os indivíduos podem, a dado momento e após avaliação das condicionantes impostas pelo campo em que se encontram, escolher sobrepor um tipo de disposições a outras para guiar a sua performance. Mais ainda, os indivíduos têm margem de manobra para recusar incorporar conhecimentos ou signifi cados particulares que lhes são transmitidos, principalmente se estes puserem em causa a sua perceção de si como possuindo um estatuto tão legítimo como os demais indivíduos para se mover num campo particular ou se lhes imputarem alguma forma de estigma. Conseguem, portanto, abrir uma brecha no processo de constrangimento estrutural de que são alvo, recorrendo à sua capacidade de desatenção reflexiva face às normas que devem regular a sua conduta, podendo escolher resistir às forças externas que os tentam modelar e agindo de forma a atingir um objetivo previamente estabelecido. Esta ideia é demonstrada pelas palavras de uma entrevistada, para a qual a ausência de 
"preocupações" e de "restrições" à demonstração pública de afetos serve um propósito maior:

Nós não temos essas preocupações na rua, nem com ninguém. [...] Se tivermos que nos beijar, ou dar a mão, ou whatever, não temos nenhuma restrição nesse aspeto. $\mathrm{E}$ também achamos que nem sequer é bom em relação às garotas; tudo aquilo que a pessoa esconde ou que transmite 'ok, aqui não vamos fazer porque o que é que os outros vão pensar?...' (Francisca, 28 anos, EDL, distrito de Setúbal)

A transposição dos para fora do espaço privado é considerada como uma forma de os "naturalizar", de forma a mostrar aos outros, no caso, às filhas, que são demonstrações passíveis de ocorrer com tanta legitimidade como quaisquer outras. Esta capacidade de transgredir fronteiras várias - espaciais, de género e de sexualidade - assenta num tipo particular de habitus: regra geral, o que diferencia as mulheres que afirmam a sua relação afetiva e, de forma associada, as suas identidades sexuais no espaço público face às que não o fazem é o facto de serem mais novas, de terem um maior número de amigos/ conhecidos com identidades sexuais não normativas nas suas redes de sociabilidade, de já terem tido/terem contacto, de alguma forma, com organizações que defendem os interesses das minorias sexuais e/ou de se assumirem como ativistas que integram o movimento LGBT. O facto de terem em torno de 30 anos de idade, salvo algumas exceções, implica que as disposições que incorporaram estão enraizadas num contexto social marcado pela versão portuguesa do da sexualização da cultura avançada por McNair (2002) e Atwood $(2006,2010)$, na medida em que a sexualidade e as questões a ela associadas irrompem no espaço público e ganham cada vez mais terreno nos discursos veiculados e nas práticas de intimidade. Este processo é especialmente marcado por dois fenómenos interligados: por um lado, pela emergência do direito ao prazer, alterando de forma acentuada a forma como as mulheres e os indivíduos com identidades sexuais não normativas passam a poder experienciar a sexualidade (Aboim, 2013), possibilitando proceder a uma rutura face às representações patriarcais que delimitavam a prática sexual ao propósito reprodutivo e, portanto, uma maior individualidade neste campo; por outro lado, pela consolidação, desde o seu surgimento no final da década de 1990, de um ativismo gay e lésbico organizado (Cascais, 2006; Santos, 2009), que forneceu elementos de autoidentificação aos indivíduos, tornou visível o cariz multiforme que a sexualidade e as relações afetivas podem assumir, assumiu como mote a igualdade e a cidadania e conseguiu alterar gradualmente, como Almeida (2010) dá conta de forma pormenorizada, o estatuto legal e social daqueles com sexualidades não normativas.

Construir e consolidar o habitus neste contexto de mudança possibilita, portanto, possuir uma reserva de disposições liberais que assumem preponderância nas experiências e práticas quotidianas, convertendo as regras de condicionadoras da ação a potenciadoras e geradoras dela, transformando estigmas em veículos de deslocação das normas.

Ainda que a classe social não assuma um papel tão vincado na definição de quais as estratégias de gestão dos afetos entre os casais que transgridem as fronteiras do espaço público, é de notar uma particularidade, que reside no facto de que existe um maior número de mulheres provenientes de lugares de classe desprivilegiados do que entre os casais que dissimulam publicamente a sua relação afetiva. Este facto pode ser decorrente de dois fenómenos. O primeiro, e adotando uma lente bourdieuana $(1994,1998)$, diz respeito a uma tentativa de inversão das relações de poder que, em decorrência da sua pertença de classe desprivilegiada e dos baixos volumes de capitais possuídos durante uma parte das suas vidas, as submeteu a uma posição de dominação social e, portanto, 
assente numa baixa amplitude de poder para negociar as suas condições de existência e para impor as suas definições e regras de funcionamento nos vários campos em que se moveram. A mobilidade social ascendente de que foram alvo posteriormente dotou-as de alguns recursos necessários para a sua entrada mais igualitária em jogos de poder e para aumentar as suas probabilidades de impor as suas visões do mundo. O segundo está relacionado com a dinâmica, já referida anteriormente, relativa ao poder diferencial no seio do casal em função da posse, ou não, de capital biogenético. Independentemente de ser a mãe gestante, ou não, aquela que se posiciona num lugar de classe de origem mais desprivilegiado, a posse deste tipo de capital determina, potencialmente, a sua maior posição de poder face à mãe não gestante, o que pode resultar na sua maior capacidade de decisão quanto à transgressão dos afetos conjugais para o espaço público. Qualquer um dos fenómenos hipotéticos acaba por dar visibilidade às mulheres originárias de classes sociais mais próximas da base da hierarquia no espaço público.

\section{Notas conclusivas}

A expressão dos afetos no espaço público é mediada por aquilo que Jackson e Scott (2004) designam de antinomias sexuais da modernidade tardia, e que se traduzem, sinteticamente, na simultaneidade de ocorrência de uma dinâmica de libertação e pluralização sexuais e de um processo de reprodução da heterossexualidade como norma a partir da qual as relações de intimidade, as práticas sexuais e as identidades devem ser construídas. Estas duas lógicas servem de base a cada uma das estratégias de gestão das identidades sexuais e conjugais fora do espaço do lar: por um lado, um panorama social assente na diversidade sexual potencia a possibilidade de afirmação, por parte de algumas das entrevistadas, da sua relação afetiva num espaço que se aparenta plural e igualitário, em termos do que pode albergar e proporcionar aos que nele se movem; por outro lado, a remissão dos afetos para o espaço privado é indicativa de que as mulheres têm consciência de estar a subverter o pressuposto da heterossexualidade como a forma "natural" de prática e de identidade, bem como as representações do que é ser uma mulher "adequada". É esta consciência que impele à dissimulação da sua relação afetiva e das suas identidades sexuais no espaço público, por referência aos ideais de feminilidade e de masculinidade que veem estar a fazer estremecer ao mesmo tempo, ao assumirem um objeto de desejo amoroso que, tradicionalmente, é reservado aos homens e ao desafiar a localização das mulheres no campo da disponibilidade permanente para indivíduos do sexo oposto (Méndez, 2009), percecionando-se como deslocadas face às normas de género e sexuais que regulam o espaço público.

31 Cada um dos tipos de estratégia é potenciado por um tipo particular de habitus das entrevistadas, que está, de algum modo, associado a cada uma das lógicas antonímicas anteriormente referidas. A afirmação pública dos afetos é protagonizada, regra geral, por mulheres mais novas, com redes de sociabilidade LGBT mais extensas, o que constitui um reflexo particular da lógica relativamente recente de entrada da sexualidade para a esfera pública, coadjuvada pelas tendências de libertação, diversificação e (suposta) democratização sexual. A ocultação é levada a cabo, maioritariamente, por mulheres de classes privilegiadas e mais velhas, com camadas antigas de disposições, incorporadas num contexto social mais limitativo no que respeita às possibilidades oferecidas em termos de práticas e de identidades sexuais, que se continuam a sobrepor às camadas mais recentes na atribuição de sentido à experiência quotidiana. A tendência para não 
ultrapassar as fronteiras do espaço público parece estar relacionada com representações do que é ser mulher com um cunho vincado de classe, compreensível à luz da história da divisão entre os espaços públicos e privados e do papel que uma classe privilegiada teve nela, com ramificações para a delimitação clara do que é ser mulher e do que é ser homem, em estreita associação com a privacidade e a publicidade, respetivamente. De facto, os discursos destas entrevistadas refletem, ainda, indiretamente, as ideias burguesas de pudor, de moralidade e de respeitabilidade feminina no espaço público através da referência à não expressão afetiva como um traço de personalidade. 0 espaço público é constituído por uma teia de relações de poder na qual estas mulheres se envolvem de modos diferentes. Apesar de os dois grupos de mulheres terem um volume de capital simbólico sufi ciente para entrar nos jogos de poder e conseguir impor a sua perspetiva, desestabilizando as normas de género e de sexualidade, algumas delas mobilizam esse capital, paradoxalmente, no sentido da reprodução dessas normas, contribuindo para a sua própria deslegitimação no espaço público. Fazem-no por via da falsa sensação de poder para "escolher" confinar os seus afetos à privacidade do lar. Contribuem, portanto, de forma contracíclica para o propósito de legitimação de outras formas de relação afetiva e de práticas e identidades de género e sexuais que as mulheres que jogam contra os poderes dominantes pretendem perseguir. Este artigo permite, então, dar conta de como, em sentido contrário à tentativa de diluição das fronteiras entre a marginalidade e a centralidade (nos termos de Meneses (2000), que aqui podem ser atribuídas ao espaço privado/às identidades sexuais não normativas e ao espaço público/à heteronormatividade, respetivamente), está em curso, concomitantemente, a sua manutenção, cujo sinal mais visível é a colocação de algumas destas mulheres no "quarto", parafraseando Vieira (2010), de acordo com a sua própria "escolha".

\section{BIBLIOGRAPHY}

ABOIM, Sofia (2008), “Género e modernidade: A construção pública do privado”, in Manuel Villaverde Cabral, Karin Wall, Sofia Aboim e Filipe Carreira da Silva (orgs.), Itinerários: A investigação nos 25 anos do ICS. Lisboa: Imprensa de Ciências Sociais: 561-582.

ABOIM, Sofia (2013), A Sexualidade dos Portugueses. Lisboa: Fundação Francisco Manuel dos Santos.

ALMEIDA, Miguel Vale de (2010), “O contexto LGBT em Portugal”, in Conceição Nogueira e João Manuel de Oliveira (orgs.), Estudo sobre a Discriminação em Função da Orientação Sexual e da Identidade de Género. Lisboa: Comissão para a Cidadania e a Igualdade de Género: 45-92.

ATWOOD, Feona (2006), “Sexed up: Theorizing the sexualization of culture”, Sexualities, 9(1): 77-94.

ATWOOD, Feona (2010), “Sexualization, sex and manners”, Sexualities, 13 (6): 742-745. BECK, Ulrich, BECK-GERNSHEIM, Elisabeth (2002), Institutionalized Individualism and its Social and Political Consequences. London: SAGE. 
BELL, David, VALENTINE, Gill (1995), “Introduction: Orientations", in David Bell e Gill Valentine (eds.), Mapping Desire: Geographies of sexualities. London: Routledge: 1-27. BLIDON, Marianne (2008), "La casuistique du baiser: L'espace publique un espace hétéronormatif", EchoGéo, 5: 1-12.

BONDI, Liz, DOMOSH, Mona (1998), “On the contours of public space: A tale of three women", Antipode, 30 (3): 270-289.

BOURDIEU, Pierre (1994), o Poder Simbólico. Lisboa: Difel.

BOURDIEU, Pierre (1998), Questions de sociologie. Paris : Les Editions de Minuit.

BOURDIEU, Pierre (2001), Meditações Pascalianas. Rio de Janeiro: Bertrand Brasil.

BOURDIEU, Pierre (2002), Esboço de uma Teoria da Prática: Precedido de três estudos da etnologia Cabila. Oeiras: Celta.

BOURDIEU, Pierre, PASSERON, Jean-Claude (1970), La Reproduction: Éléments d'une théorie du système d'enseignement. Paris: Les Editions de Minuit.

BRANDÃO, Ana Maia (2007), “'E se tu fosses um rapaz? Homo-erotismo feminino e construção social da identidade", Dissertação de Doutoramento em Sociologia. Braga: Universidade do Minho.

BROWNE, Kath, LIM, Jason, BROWN, Gavin (2007), Geographies of Sexualities: Theory, practice and politics. Farnham: Ashgate.

CASCAIS, António Fernando (2006), “Diferentes como só nós. O associativismo GLBT português em três andamentos”, Revista Crítica de Ciências Sociais, 76: 109-126.

COSTA, Carlos Gonçalves, OLIVEIRA, João Manuel de, NOGUEIRA, Conceição (2010), “Os discursos das pessoas LGBT", in Conceição Nogueira e João Manuel de Oliveira (orgs.), Estudo sobre a Discriminação em Função da Orientação Sexual e da Identidade de Género. Lisboa: Comissão para a Cidadania e a Igualdade de Género: 211-241.

DUNCAN, Nancy (1996), "Renegotiating gender and sexuality in public and private spaces", in Nancy Duncan (ed.), BodySpace: Destabilizing geographies of gender and sexuality. London: Routledge: 127-145.

FERREIRA, Eduarda (2011), “Geographies of (in)equalities: space and sexual identities”, in Regina Salvador, Ana Firmino, Cristina Ponte e Eduarda Ferreira (eds.), Proceedings of Geographies of Inclusion: Challenges and opportunities. Lisboa: e-GEO: 36-60.

FOUCAULT, Michel (1999), História da Sexualidade: A vontade de saber. Rio de Janeiro: Edições Graal.

GABB, Jacqui (2005), “Locating lesbian parent families: Everyday negotiations of lesbian motherhood in Britain”, Gender, Place \& Culture: A Journal of Feminist Geography, 12 (4): 419-432.

GIDDENS, Anthony (1992), A Transformação da Intimidade: Sexualidade, amor e erotismo nas sociedades modernas. São Paulo: Fundação Editora da UNESP.

GOFFMAN, Erving (1963), Stigma: Notes on the management of spoiled identity. Londres: Penguin. GOFFMAN, Erving (1993), A Apresentação do Eu na Vida de Todos os Dias. Lisboa: Relógio d'Água. GREENBERG, David (1988), The Construction of Homosexuality. Chicago: The University of Chicago Press.

HABERMAS, Jurgen (1991), The Structural Transformation of the Public Sphere. Cambridge: The MIT Press.

HUNT, Lynn (2009), "Revolução Francesa e vida privada”, in Michelle Perrot (org.), História da Vida Privada: Da Revolução Francesa à primeira guerra. São Paulo: Editora Schwarcz: 18-46. 
JACKSON, Stevi, SCOTT, Sue (2004), “Sexual antinomies in late modernity", Sexualities: 7(2), 233-248.

MACHADO, Fernando Luís et al. (2003), “Classes sociais e estudantes universitários: Origens, oportunidades e orientações", Revista Crítica de Ciências Sociais, 66: 45-80.

McNAIR, Brian (2002), Striptease Culture: Sex, media and the democratization of desire. London: Routledge.

MÉNDEZ, Raquel Platero (2009), “La construcción del sujeto lésbico”, LES Online, 1(1), 36-44.

MENESES, Inês (2000), “Intimidade, norma e diferença: a modernidade gay em Lisboa”, Análise Social, XXXIV (153): 933-955.

MOITA, Maria Gabriela (2001), Homossexualidade de Dois Lados do Espelho, Dissertação de Doutoramento em Ciências Biomédicas. Porto: Instituto de Ciências Biomédicas de Abel Salazar. MOTA, Nelson (2006), A Arquitectura do Quotidiano: Público e privado no espaço doméstico da burguesia portuense nos finais do século XIX, Dissertação de Mestrado em Arquitectura, Território e Memória. Coimbra: Faculdade de Ciência e Tecnologia da Universidade de Coimbra.

OLIVEIRA, João Manuel de, GONÇALVES, Carlos, NOGUEIRA, Conceição (2013), “The workings of homonormativity: Lesbian, gay, bisexual, and queer discourses on discrimination and public display of affections in Portugal", Journal of Homosexuality, 60 (10): 1475-1493.

PERROT, Michelle (2009), “Outrora, em outro lugar”, in Michelle Perrot (org.), História da Vida Privada: Da Revolução Francesa à primeira guerra. São Paulo: Editora Schwarcz: 14-17.

RICHARDSON, Diana (2004), “Locating sexualities: From here to normality”, Sexualities, 7(4): 391-411.

RODÓ-DE-ZÁRATE, Maria (2013), “Young lesbians negotiating public space: an intersectional approach through spaces", Children's Geographies, 13(4): 413-434.

SANTOS, Ana Cristina (2009), "Molduras públicas de performatividade queer e representação mediática em Portugal”, ex aqueo, 20: 97-112.

SENNETT, Richard (1977), The Fall of Public Man. London: Penguin Books.

SLATER, Don (1998), "Public/Private”, in Chris Jenks (ed.), Core Sociological Dichotomies, London: Sage Publications: 138-150.

VALENTINE, Gill (1993), “(Hetero)sexing space: Lesbian perceptions and experiences of everyday spaces", Environment and Planning: Society and Space, 11(4): 395-413.

VIEIRA, Paulo Jorge (2010), “Aeminiumqueer, a cidade armário: Quotidianos lésbicos e gays em espaço urbano", Revista Latino-americana de Geografia e Gênero, 1(1): 5-13.

WACQUANT, Loic (2007), “Esclarecer o habitus”, Educação \& Linguagem, 16: 63-71.

WEEKS, Jeffrey (1986), Sexuality. New York: Routledge.

\section{NOTES}

1. Texto intitulado "The personal is political", originalmente publicado em 1970, na antologia de textos Notes from the Second Year: Women's Liberation, editada por Shulamith Firestone e Anne Koedt. 
2. Classe social de origem, de acordo com a tipologia ACM, consultada em Machado et al. (2003). No caso, refere-se a profi ssionais técnicos e de enquadramento.

\section{ABSTRACTS}

Com base em material empírico proveniente de entrevistas semiestruturadas realizadas a 40 mulheres que integram casais do mesmo sexo, este artigo pretende dar conta dos modos como é feita a gestão da expressão dos afetos no espaço público. Argumenta-se existirem dois tipos de estratégias mais ou menos bem definidas que são mobilizadas por parte destes casais nas interações públicas: por um lado, e de forma mais comum, uma estratégia de ocultação, caracterizada pela invisibilidade de manifestações afetivas entre os casais fora do espaço privado; por outro lado, uma estratégia de afirmação, configurada como uma transgressão das fronteiras simbólicas do espaço público através da visibilidade de manifestações de carinho. A pertença geracional, a classe social de origem e a configuração das redes de sociabilidade das mulheres determinam a adoção de uma ou de outra estratégia.

Considering empirical data collected through semi-structured interviews to women from samesex couples, this paper intends to show how the expression of affections is managed in public spaces. It can be argued that two relatively well defined strategies are mobilized by these couples in their public interactions: on the one hand, there is a morefrequently mobilized concealment strategy characterized by the invisibility of affective manifestations between the women outside the private space; on the other hand, there is an affirmative strategy, configured as a transgression of the symbolic boundaries of the public space through the visibility of expressions of affection. The generational belonging, the social class of origin and the dimension of women's sociability networks delineate the adoption of one strategy or the other

À partir de données empiriques tirées des entrevues semi-structurées avec 40 femmes qui font partie des couples de même sexe, cet article vise à expliquer comment elle est faite la gestion de l'expression de l'affection dans l'espace public. Il est soutenu qu'il y a deux types de stratégies plus ou moins bien définis qui sont mobilisés pour ces couples dans les interactions ordinaires: d'un côté, une stratégie plus commun de dissimulation, caractérisée par l'invisibilité des manifestations d'affection parmi les couples dehors de l'espace privé; d'un autre côté, une stratégie d'affirmation, qui constitue une transgression des frontières symboliques de l'espace public dans les expressions de la visibilité de l'affection. De l'âge, la classe sociale d'origine et la configuration des réseaux sociaux des femmes délimitent l'adoption de l'une ou l'autre stratégie.

\section{INDEX}

Mots-clés: couple de femmes, espace public, affections, dissimulation, affirmation.

Keywords: female same-sex couples, public space, concealment, affirmation

Palavras-chave: casais de mulheres, espaço público, afetos, ocultação, afi rmação. 


\section{AUTHOR}

\section{TÂNIA CRISTINA MACHADO}

Investigadora júnior do Centro Interdisciplinar de Ciências Sociais - Polo UMinho

(CICS.NOVA.UMinho). Bolseira da Fundação para a Ciência e a Tecnologia ao abrigo do projeto de Doutoramento

em Sociologia intitulado "Representações das mães lésbicas sobre a maternidade lésbica e estratégias de gestão da identidade maternal deteriorada" (SFRH/BD/89837/2012). Endereço de correspondência: CICS. NOVA.UMinho, Campus de Gualtar, 4710-057 Braga

taniacsmachado@ics.uminho.pt. 